\title{
Boosted influenza-specific $T$ cell responses after H5N1 pandemic live attenuated influenza virus vaccination
}

\section{OPEN ACCESS}

\section{Edited by: \\ Shakti Singh, \\ University of Alberta, Canada}

Reviewed by:

Beatrice Jahn-Schmid,

Medical University of Vienna, Austria

David K. Cole,

Cardiff University, UK

*Correspondence:

Kanta Subbarao,

Laboratory of Infectious Diseases, NIAID, NIH BIdg 33, Room 3E13C.1,

33 North Drive, MSC 3203 ,

Bethesda, MD 20892-3203, USA

ksubbarao@niaid.nih.gov;

Tao Dong,

Human Immunology Unit, Weatherall

Institute of Molecular Medicine,

University of Oxford, Headington,

Oxford, OX3 9DS, UK

tao.dong@imm.ox.ac.uk

${ }^{+}$YanChun Peng and Beibei Wang have contributed equally to this work.

Specialty section:

This article was submitted to Immunotherapies and Vaccines, a section of the journal

Frontiers in Immunology

Received: 27 February 2015

Accepted: 18 May 2015

Published: 02 June 2015

Citation:

Peng $Y$, Wang $B$, Talaat $K$, Karron $R$, Powell TJ, Zeng H, Dong D, Luke CJ,

McMichael A, Subbarao $K$ and

Dong T (2015) Boosted

influenza-specific $T$ cell responses after H5N1 pandemic live attenuated

influenza virus vaccination.

Front. Immunol. 6:287.

doi: 10.3389/fimmu.2015.00287
YanChun Peng ${ }^{1 \dagger}$, Beibei Wang ${ }^{1,2 \dagger}$, Kawsar Talaat ${ }^{3}$, Ruth Karron ${ }^{3}$, Timothy J. Powell ${ }^{1}$, Hui Zeng ${ }^{2}$, Danning Dong ${ }^{1}$, Catherine J. Luke ${ }^{4}$, Andrew McMichael ${ }^{1}$, Kanta Subbarao ${ }^{4 *}$ and Tao Dong ${ }^{1 *}$

\begin{abstract}
${ }^{1}$ MRC Human Immunology Unit, Weatherall Institute of Molecular Medicine, University of Oxford, Oxford, UK, ${ }^{2}$ Institute of Infectious Diseases, Beijing Ditan Hospital, Capital Medical University, Beijing, China, ${ }^{3}$ Center for Immunization Research, Johns Hopkins University Bloomberg School of Public Health, Baltimore, MD, USA, ${ }^{4}$ Laboratory of Infectious Diseases, National Institute for Allergy and Infectious Disease, National Institutes of Health, Bethesda, MD, USA
\end{abstract}

Background: In a phase I clinical trial, a H5N1 pandemic live attenuated influenza virus (pLAIV) VN2004 vaccine bearing avian influenza H5N1 hemagglutinin (HA) and NA genes on the A/Ann Arbor cold-adapted vaccine backbone displayed very restricted replication. We evaluated T cell responses to H5N1 pLAIV vaccination and assessed pre-existing $T$ cell responses to determine whether they were associated with restricted replication of the H5N1 pLAIV.

Method: ELISPOT assays were performed using pools of overlapping peptides spanning the entire H5N1 proteome and the HA proteins of relevant seasonal H1N1 and H3N2 viruses. We tested stored peripheral blood mononuclear cells (PBMCs) from 21 study subjects who received two doses of the H5N1 pLAIV. The PBMCs were collected 1 day before and 7 days after the first and second pLAIV vaccine doses, respectively.

Result: $T$ cell responses to conserved internal proteins M and NP were significantly boosted by vaccination $(p=0.036)$. In addition, H5N1 pLAIV appeared to preferentially stimulate and boost pre-existing seasonal influenza virus HA-specific $T$ cell responses that showed low cross-reactivity with the $\mathrm{H} 5 \mathrm{HA}$. We confirmed this observation by $\mathrm{T}$ cell cloning and identified a novel HA-specific epitope. However, we did not find any evidence that pre-existing $T$ cells prevented pLAIV replication and take.

Conclusion: We found that cross-reactive $T$ cell responses could be boosted by pLAIV regardless of the induction of antibody. The impact of the "original antigenic sin" phenomenon in a subset of volunteers, with preferential expansion of seasonal influenza-specific but not H5N1-specific T cell responses merits further investigation.

Keywords: influenza, H5N1, vaccine, T cells, LAIV, peptide, epitope, antigenic sin

\section{Introduction}

Influenza is a global public health problem, with seasonal epidemics caused by human H1N1, $\mathrm{H} 3 \mathrm{~N} 2$, and $\mathrm{B}$ viruses, and sporadic disease caused by avian influenza A viruses, which can lead 
to severe illness in humans (1-4). Live attenuated influenza vaccines (LAIV) that contain the A/Ann Arbor cold-adapted (AA ca) backbone (5) are immunogenic and protective and are licensed for protection against seasonal influenza (6-8). We have generated and evaluated candidate live attenuated vaccines for pandemic use (pLAIVs) bearing avian influenza A hemagglutinin (HA) and neuraminidase (NA) genes on the AA ca vaccine backbone. The H5N1 pLAIV (VN2004) bearing the HA and NA genes from the A/Vietnam/1203/2004 (H5N1) virus was evaluated in a phase I clinical trial (NCT00347672) (9). The infectivity of the H5N1 pLAIV was assessed by virus isolation and rRT-PCR amplification of vaccine virus from daily nasal washes and the immunogenicity of the vaccine was assessed by serologic methods including hemagglutination inhibition (HAI) and microneutralization and ELISA assays. The replication of the vaccine virus was highly restricted and the vaccine failed to elicit robust antibody responses (9).

Although antibody responses to inactivated influenza vaccine correlate with protection, several lines of evidence show that postvaccination antibody titers are not the sole surrogate for vaccine efficacy, especially for LAIV (10-13). Several studies demonstrate that regardless of the presence of the antibody, influenza-specific T cell responses correlate with viral clearance $(14,15)$. The "Cleveland Family study" showed that protection from influenza correlated with $\mathrm{T}$ cell responses, and cross-reactive $\mathrm{T}$ cell responses might contribute to the protection (16). Therefore, as suggested by Schotsaert et al., the correlation of vaccine efficacy with alternative measures of immune function such as influenza-specific $\mathrm{T}$ cell responses warrants further attention (17).

In this study, we evaluated the $\mathrm{T}$ cell responses in peripheral blood mononuclear cells (PBMCs) from the cohort of study subjects who received two doses of the $\mathrm{H} 5 \mathrm{~N} 1 \mathrm{VN} 2004$ ca vaccine approximately 50 days apart (9). T cell responses to overlapping peptide pools spanning the entire $\mathrm{H} 5 \mathrm{~N} 1$ proteome, as well as the HA proteins of relevant seasonal influenza viruses, were evaluated before and 7 days after each vaccination. We found that $\mathrm{T}$ cell responses with effector phenotypes were boosted by vaccination, regardless of vaccine infectivity or the serum HAI titer elicited. The potential role of pre-existing $\mathrm{T}$ cell responses in restricting the replication of $\mathrm{H} 5 \mathrm{~N} 1$ pLAIV was also evaluated.

\section{Materials and Methods}

\section{Study Population}

Nineteen healthy volunteers received two doses of the H5N1 VN 2004 pLAIV approximately 50 days apart, and two additional volunteers received only one dose (9). Blood samples were taken from each of the study subject at four time points: pre-vaccination, 7 days after the first dose of vaccine, 1 day prior to the second dose of vaccine, and 7 days after the second dose of vaccine. The study subjects were divided into two groups according to their infection status. Infection with the vaccine virus was inferred if the study subjects shed vaccine virus in culture, were RT-PCR positive after day 1 , and/or demonstrated a fourfold or greater rise in serum antibody titer (9). Ethical approval was obtained from the
Committee on Human Research Institutional Review Board (IRB) of the Johns Hopkins Bloomberg School of Public Health and the Institutional Biosafety Committee of Johns Hopkins University. Informed consent was obtained from all participating individuals prior to the study (9). The ClinicalTrials.gov identifier for this study is NCT00347672.

In order to understand the priming of the immune system induced by the H5N1 pLAIV, subjects who received two doses of the H5N1 VN 2004 pLAIV were contacted 4 years after receipt of the pLAIV and invited to participate in a follow-up study. Eleven subjects returned for this additional booster dose of $45 \mu \mathrm{g}$ of the $\mathrm{H} 5 \mathrm{~N} 1$ inactivated unadjuvanted subvirion influenza vaccine (ISIV) (NCT01109329) (18). Antibody responses were measured after the boost dose, and compared with subjects who had received a non-H5N1 pLAIV or the ISIV alone (18).

\section{Synthetic Peptides for T Cell Analysis}

A total of 890 15- to 18-mer peptides overlapping by 10 amino acid residues and spanning the full avian influenza $\mathrm{H} 5 \mathrm{~N} 1$ proteome and seasonal influenza $\mathrm{H} 3 \mathrm{~N} 2 / \mathrm{H} 1 \mathrm{~N} 1 \mathrm{HA}$ proteins was synthesized by Sigma-Aldrich (Haverhill, Suffolk, UK) and used in our previous study (19). The peptides were dissolved in DMSO (Sigma-Aldrich) at $40 \mathrm{mg} / \mathrm{ml}$ and diluted with RPMI 1640 (SigmaAldrich) to a concentration of $2 \mathrm{mg} / \mathrm{ml}$ (long-term stock, stored at $-80^{\circ} \mathrm{C}$ ) before being individually filtered and combined into different pools: H1 HA, H3 HA, H5 HA, M, and NP (40-90 peptides/pool)

\section{Ex Vivo IFN $\gamma$ ELISPOT Assay}

Cryopreserved PBMCs were thawed in a $37^{\circ} \mathrm{C}$ water bath and re-suspended in RPMI 1640 supplemented with $2 \% \mathrm{v} / \mathrm{v}$ heat-inactivated fetal calf serum (FCS, Sigma-Aldrich), $2 \mathrm{mM} \mathrm{L-}$ glutamine (Sigma-Aldrich), $1 \% \mathrm{v} / \mathrm{v}(100 \mathrm{U} / \mathrm{ml})$ penicillin streptomycin (Sigma-Aldrich) (R2 medium), and $60 \mu \mathrm{g} / \mathrm{ml}$ DNase solution (Type IV, Sigma-Aldrich) for $15 \mathrm{~min}$ at $37^{\circ} \mathrm{C}$. Cells were washed and re-suspended in R10 medium (RPMI1640, 10\% FCS, $2 \mathrm{mM}$ L-glutamine, and $1 \%$ PenStrep) and rested overnight at a concentration of $10^{6}$ cells $/ \mathrm{ml}$. PBMCs $(200,000)$ with $2 \mu \mathrm{g} / \mathrm{ml}$ the concentration of a single peptide in the pool or $400 \mathrm{~T}$ cells/clone with 20,000 peptide-pulsed Epstein-Barr virus transformed B cells were used in standard human IFN $\gamma$ ELISPOT assays as described elsewhere (15). In brief, assays were performed in 96-well MultiScreen filter plates (Merck Millipore, Watford, Hertfordshire, UK) coated with $10 \mu \mathrm{g} / \mathrm{ml}$ anti-IFN- $\gamma$ (1-DIK, Mabtech, Nacka Strand, Sweden). Phytohemagglutinin $(5 \mu \mathrm{g} / \mathrm{ml}$, PHA, final concentration $1 \mu \mathrm{g} / \mathrm{ml}$; Alere, Stockport, Cheshire, UK) was used as a positive control. Plates were incubated for $16 \mathrm{~h}$ at $37^{\circ} \mathrm{C}$ and $5 \% \mathrm{CO}_{2}$. Spot enumeration was performed with an AID ELISPOT reader system (Autoimmun Diagnostika $\mathrm{GmbH}$, Ebinger Strasse, Straßberg, Germany). To quantify antigen-specific responses, mean spots of the control wells were subtracted from the positive wells, and the results are expressed as SFU $/ 10^{6}$ PBMCs. Responses were considered positive if results were at least three times the mean of the quadruplicate negative control wells and $>25$ SFU $/ 10^{6}$ PBMCs. If negative control wells 
had $>30$ SFU $/ 10^{6}$ PBMCs or positive control wells (PHA stimulation) were negative, the results were excluded from further analysis.

\section{Depletion of $\mathrm{CDB}^{+} \mathbf{T}$ Cells}

$\mathrm{CD}^{+} \mathrm{T}$ and $\mathrm{CD}^{+} \mathrm{T}$ cells were depleted with M-450 Dynabeads (Invitrogen, Dynal, Oslo, Norway) according to manufacturers' instructions. This method has been validated and widely used (15). Briefly, PBMCs from the same patient were divided and incubated with anti-CD8 or anti-CD4 mAbs conjugated to ferrous beads in $0.1 \%$ FCS PBS medium at $4^{\circ} \mathrm{C}$ for 30 min. The $\mathrm{CD}^{+}$and $\mathrm{CD}^{+}{ }^{+} \mathrm{T}$ cells were removed using a magnet stand (Invitrogen, Dynal). The efficiency of depletion was assessed using a $\mathrm{CyAn}^{\mathrm{TM}}$ ADP flow cytometer (Dako, Ely, UK) and FlowJo software (Tree Star Inc., Ashland, OR, USA). The frequency of $\mathrm{CD}^{+} \mathrm{T}$ cells and $\mathrm{CD}^{+} \mathrm{T}$ cells was $<1 \%$ after depletion.

\section{Tetramer Staining and Multicolor Flow Cytometry} Cryopreserved PBMCs were thawed as described above. A total of $1 \times 10^{6}$ live PBMCs were labeled with tetramer-PE:HLA-A ${ }^{\star} 0201$ complexed with $\mathrm{M1}_{58-66}$ peptide GILGFVFTL, produced inhouse using standard methods (20), and incubated for $15 \mathrm{~min}$ at $37^{\circ} \mathrm{C}$. Cells were then incubated with CD8-PerCP and CD4Pacific Blue (eBiosciences, Hatfield, UK), as well as a panel of antibodies for cell activation and differentiation markers: CD28FITC, HLA-DR-APC, CD38-PE-Cy7, and CD27-APC-H7. Cells allocated to the intracellular panels were permeabilized with Perm/fix (BD, Oxford, UK) for $15 \mathrm{~min}$ and washed twice with $1 \times$ perm/washing buffer (BD). Cells were then labeled with PerforinFITC (D48, Genprobe, Manchester, UK) or GranzymeA-FITC and GranzymeB-PB (Biolegend, London, UK). Cells were subsequently washed twice with $1 \times$ perm/washing buffer and fixed in $\mathrm{BD}$ cellfix (BD). All antibodies were from Becton Dickinson (BD, Oxford, UK) unless otherwise stated. Cell events were acquired on a nine-color CyAn Cytometer (Dako, Ely, UK), and data files were analyzed using FlowJo software. Data were analyzed using a forward side scatter gate followed by CD8 gating, then tetramer gating within the $\mathrm{CD} 8^{+}$population. These cells were then analyzed for percentage expression of a particular marker using unstained and $\mathrm{CD}^{+}$tet $^{-}$populations to determine where to place the gates. Single-color samples were run for compensation, and fluorescence minus one (FMO) control samples were also applied to determine positive and negative populations, as well as channel spillover.

\section{T Cell Clones and EBV-Transformed B Cell Line}

Cytotoxic $\mathrm{T}$ cell (CTL) clones specific for peptide H1 HA-56 were generated by limiting dilution from the PBMCs of study subject ID24 and maintained as described by Dong et al. (21). An autologous EBV-transformed B cell line was also generated from this subject.

\section{Intracellular Staining and Flow Cytometry}

The following directly conjugated monoclonal antibodies were obtained from BD Biosciences (BD, Oxford, UK): IFN- $\gamma$ (FITC), TNF- $\alpha$ (APC), CD107a (PE), CD3 (APC-H7), and CD8

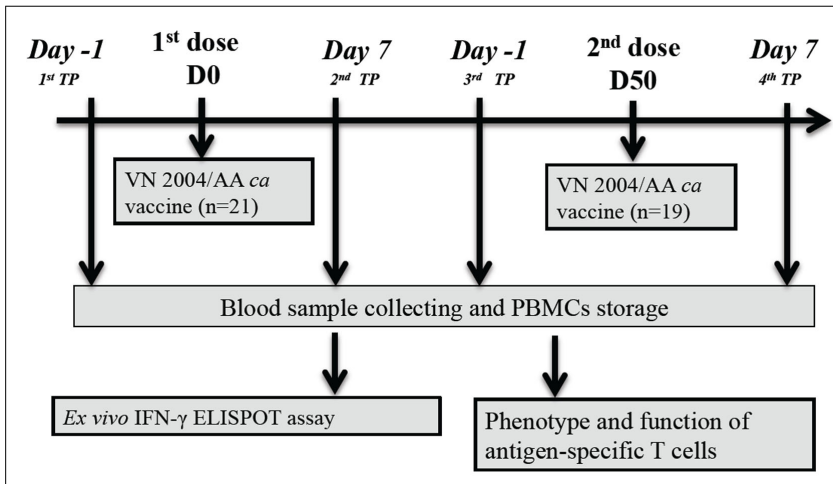

FIGURE 1 | Flow diagram of the clinical trial study design.

(PE-Cy7). Antigen-specific $\mathrm{CD}^{+} \mathrm{T}$ cell clones were stimulated with peptide-pulsed autologous $\mathrm{B}$ cells in the presence of antiCD107a for $1 \mathrm{~h}$ and incubated with $0.7 \mu \mathrm{g} / \mathrm{ml}$ monensin (BD Biosciences) and $10 \mu \mathrm{g} / \mathrm{ml}$ Brefeldin A (BD Biosciences) for an additional $5 \mathrm{~h}$ at $37^{\circ} \mathrm{C}$. Negative controls included un-stimulated cells. $\mathrm{CD}^{+} \mathrm{T}$ cell populations producing cytokines were fixed and stained as described above and detected by flow cytometry.

\section{Statistical Analysis}

All statistical analyses were performed using Prism 6 (GraphPad Software). $p$-values were calculated using the Wilcoxon matchedpairs signed rank test or the Mann-Whitney test. $p<0.05$ was regarded as statistically significant.

\section{Results}

\section{Study Subjects and Specimens}

As described by Karron et al. (4), 21 healthy volunteers were enrolled in this phase I clinical trial and received the $\mathrm{H} 5 \mathrm{~N} 1 \mathrm{VN}$ 2004 ca vaccine intranasally. With the exception of 2 study subjects (ID31 and ID41), the remaining 19 study subjects received a second dose of vaccine approximately 50 days later. As shown in Figure 1, blood samples were taken from each study subject at four time points (TP): pre-vaccination (first TP), 7 days after the first dose (second TP), 1 day prior to the second dose (third TP), and 7 days after the second dose (fourth TP). Stored frozen PBMCs were used for this study. Infection with vaccine virus occurred in 12 study subjects.

\section{H5N1 pLAIV Vaccine Boosts Influenza-Specific T Cell Responses}

Significantly elevated $\mathrm{T}$ cell responses were observed to H5 HA $(p=0.0068$, Figure 2A) after first and second dose of vaccine; elevated $\mathrm{T}$ cell responses to $\mathrm{M}$ and NP proteins were also observed (Figure 2B, $p=0.036$ ) (Figure 2B). We found that 12 of 21 study subjects showed elevated $\mathrm{T}$ cell responses to the highly conserved $\mathrm{M}$ and NP proteins after the first and/or second dose of pLAIV, regardless of whether they had confirmed vaccine virus infection (Figure 2C). These responses did not correlate with the antibody responses following ISIV boost administered in a follow-up study (18). 

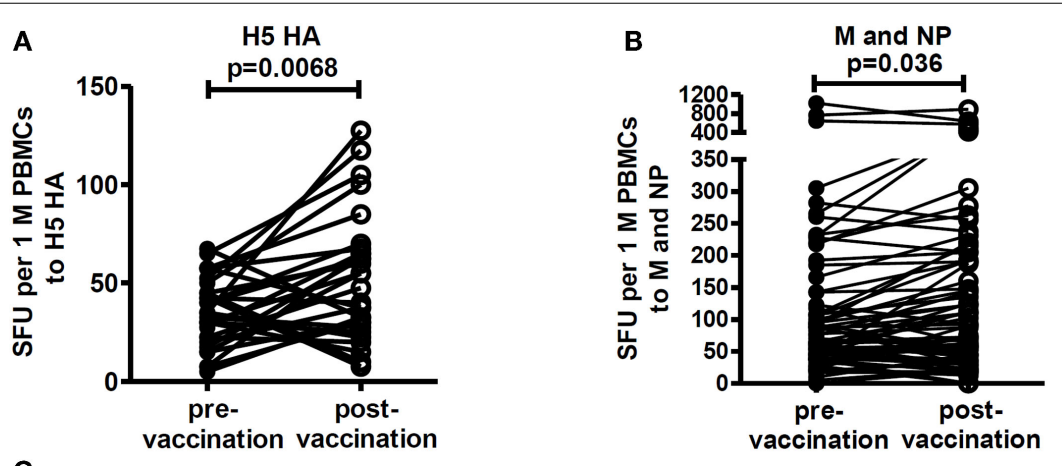

C

\begin{tabular}{|c|c|c|c|c|c|c|c|}
\hline \multirow[t]{2}{*}{ Protein } & \multirow[t]{2}{*}{ ID } & \multicolumn{4}{|c|}{ ELISPOT data: SFU/million PBMCs } & \multirow[t]{2}{*}{ Infection } & \multirow{2}{*}{$\begin{array}{l}\text { Seroconversion } \\
\text { after H5N1 ISIV }\end{array}$} \\
\hline & & $\mathbf{1}^{\text {st }} \mathbf{T P}$ & $2^{\text {nd }} T P$ & $3^{\text {rd }} \mathrm{TP}$ & $4^{\text {th }} \mathrm{TP}$ & & \\
\hline \multirow[t]{5}{*}{$\mathbf{M}$} & 22 & 23 & $90 *$ & $105^{*}$ & $192 *$ & $\mathrm{~N}^{\mathrm{b}}$ & $\mathrm{P}^{\mathrm{c}}$ \\
\hline & 26 & 90 & 27 & 25 & $75^{*}$ & $\mathrm{~N}$ & $\mathrm{n} / \mathrm{d}$ \\
\hline & 30 & 3 & $\mathrm{n} / \mathrm{a}^{\mathrm{d}}$ & $38^{*}$ & 0 & $\mathrm{~N}$ & $\mathrm{P}$ \\
\hline & 28 & 42 & $\mathrm{n} / \mathrm{a}$ & 10 & $45^{*}$ & $\mathrm{P}\left(1^{\mathrm{st}} / 2^{\mathrm{nd}}\right)$ & $\mathrm{n} / \mathrm{d}$ \\
\hline & 37 & 55 & 23 & 28 & $73 *$ & $\mathrm{P}\left(2^{\text {nd }}\right)$ & $\mathrm{n} / \mathrm{d}$ \\
\hline \multirow[t]{9}{*}{$\mathbf{N P}$} & 22 & 45 & 57.5 & $100 *$ & $145^{*}$ & $\mathrm{~N}$ & $\mathrm{n} / \mathrm{d}$ \\
\hline & 23 & 87.5 & 92.5 & 37.5 & 205* & $\mathrm{N}$ & $\mathrm{n} / \mathrm{d}$ \\
\hline & 24 & 230 & 502* & 232 & 263 & $\mathrm{~N}$ & $\mathrm{n} / \mathrm{d}$ \\
\hline & 26 & 93 & 53 & $\mathrm{n} / \mathrm{a}$ & $140 *$ & $\mathrm{~N}$ & $\mathrm{n} / \mathrm{d}$ \\
\hline & 33 & 20 & 18 & $83 *$ & $110^{*}$ & $\mathrm{~N}$ & $\mathrm{P}$ \\
\hline & 35 & 75 & 143 & 45 & $113^{*}$ & $\mathrm{~N}$ & $\mathrm{~N}$ \\
\hline & 36 & 108 & 215* & 143 & 145 & $\mathrm{P}\left(1^{\mathrm{st}} / 2^{\mathrm{nd}}\right)$ & $\mathrm{N}$ \\
\hline & 39 & 53 & $125^{*}$ & 38 & 58 & $\mathrm{P}\left(2^{\text {nd }}\right)$ & $\mathrm{P}$ \\
\hline & 40 & 93 & $220^{*}$ & 88 & 123 & $\mathrm{P}\left(1^{\mathrm{st}}\right)$ & $\mathrm{P}$ \\
\hline
\end{tabular}

${ }^{\mathrm{a}}$ ISIV = inactivated $\mathrm{H} 5 \mathrm{~N} 1$ subvirion influenza vaccine. ${ }^{\mathrm{b}} \mathrm{N}=$ negative. ${ }^{\mathrm{c}} \mathrm{P}=$ positive.

${ }^{\mathrm{d}} \mathrm{n} / \mathrm{d}$ : Not done. Subject did not receive ISIV. ${ }^{\mathrm{e}} \mathrm{n} / \mathrm{a}$ : Not available due to limited cell number.

$* \geq 2$ fold increment after first or second dose of pLAIV

FIGURE 2 | Elevated T cell responses after each vaccination. T cell responses at all four time points (TP) were screened by ex vivo IFN- $\gamma$ ELISPOT using overlapping peptides from $\mathrm{H} 1 \mathrm{HA}, \mathrm{H} 3 \mathrm{HA}, \mathrm{H} 5 \mathrm{HA}$, and H5N1 VN 2004 Matrix proteins (M1 and $\mathrm{M} 2$ ) and Nucleoprotein. $n=2$ replicates.

(A) Comparison of $\mathrm{T}$ cell responses targeting H5 HA peptides pre- and post- first and second vaccination $(n=21)$. (B) Comparison of $T$ cell responses targeting internal proteins $\mathrm{M}(n=20)$ and NP $(n=19)$ pre- and post- first and second vaccination. $p$-values were calculated using the Wilcoxon matched-pairs signed rank test. (C) Study subjects who showed $>2$-fold elevated $\mathrm{T}$ cell responses to M and NP peptides after vaccination.

\section{The H5N1 pLAIV is able to Stimulate Cross-Reactive T Cell Responses with an Effector Phenotype, Specific to Internal Viral Proteins}

We next evaluated the phenotype of antigen-specific $\mathrm{CD} 8^{+} \mathrm{T}$ cells by staining PBMCs with an MHC class I tetramer specific to an HLA-A0201-restricted M1 protein (58-66) epitope and a panel of antibodies specific for cell activation and cytotoxicity markers. Figure $\mathbf{3 A}$ displays the gating strategy used in flow cytometry. $\mathrm{T}$ cells from two study subjects (ID36 and ID42) who were infected with the vaccine virus were positively stained with this tetramer. Figure 3B clearly demonstrates that the proportion of $\mathrm{CD}^{+}$ tetramer ${ }^{+} \mathrm{T}$ cells increased after vaccination. In study subject ID36, the $\mathrm{CD}^{+}{ }^{+}$tetramer ${ }^{+} \mathrm{T}$ cells expanded from 0.038 to $0.067 \%$ after the first dose of vaccine. Although the size of the antigenspecific $\mathrm{T}$ cell population shrank slightly thereafter, from $0.067 \%$ 7 days after the first dose of vaccine to $0.057 \% 7$ days following the second dose of vaccine, it was still greater than the baseline level. In study subject ID42, the $\mathrm{CD}^{+}{ }^{+}$tetramer ${ }^{+} \mathrm{T}$ cells were boosted after each dose of vaccine, with an approximately $0.05 \%$ increase post-vaccination. The number of antigen-specific $\mathrm{T}$ cells increased, and there was an enhancement in expression levels of cell activation and cytotoxicity molecules, such as CD38, HLA$\mathrm{DR}$, and perforin, on the $\mathrm{T}$ cells (Figure $3 \mathrm{C}$ ), indicating that the $\mathrm{H} 5 \mathrm{~N} 1$ pLAIV could boost $\mathrm{CD}^{+}{ }^{+} \mathrm{T}$ cells specific to internal viral proteins with effector functions. Moreover, we also observed stronger systematic activation of $\mathrm{CD} 8^{+} \mathrm{T}$ cells from study subjects who were infected with the vaccine virus. As shown in Figure 3D, the expression level of CD38 on the surface of CD8 ${ }^{+} \mathrm{T}$ cells was higher after each dose of vaccine compared to pre-vaccination levels.

\section{Elevated HA-Specific T Cell Responses to Seasonal Influenza Viruses with Low Cross-Reactivity to H5N1 HA Peptides}

We also observed elevated T cell-specific responses to HA proteins of seasonal influenza viruses ( $\mathrm{H} 1$ and $\mathrm{H} 3$ ) in 6 out of 21 subjects following receipt of the H5 pLAIV vaccine (Figure 4A). The 

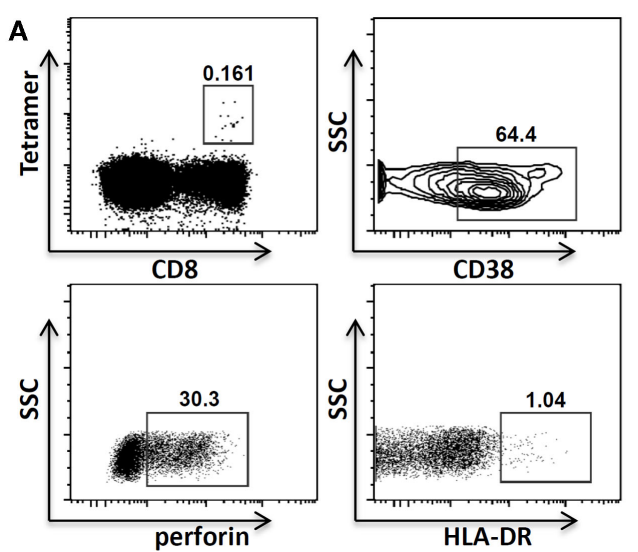

C

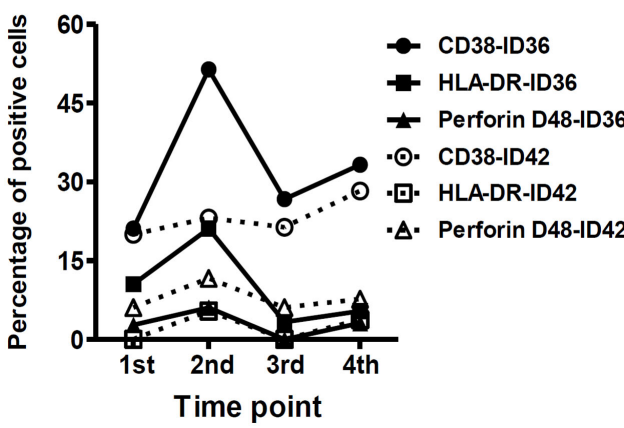

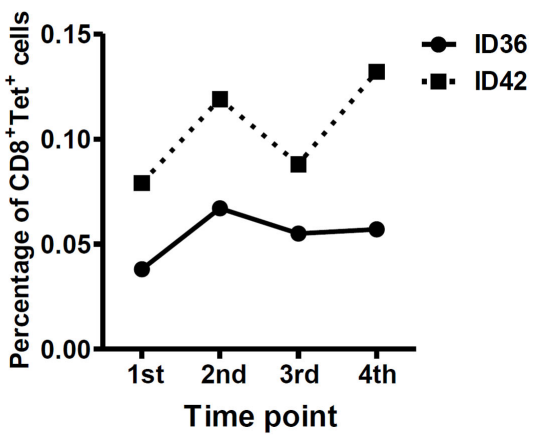

D

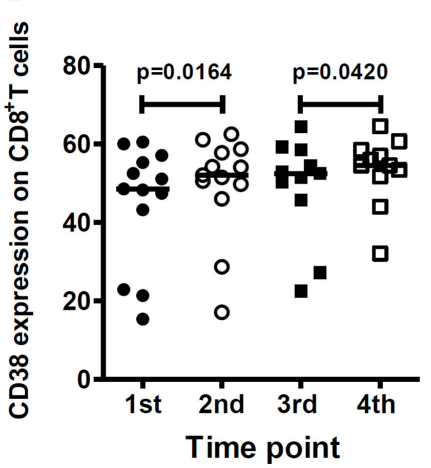

FIGURE 3 | HLA-A*0201 M158-66-specific T cells were boosted and showed better effector function after each vaccine dose. (A) Gating strategy. Gating of $\mathrm{CD}^{+}{ }^{+}$tetramer ${ }^{+}$cells, $\mathrm{CD}^{+} \mathrm{CD}^{+}{ }^{+}$cells, $\mathrm{CD} 8^{+}$ perforin ${ }^{+}$cells, and $\mathrm{CD}^{+}{ }^{+} \mathrm{HLA}_{-} \mathrm{DR}^{+}$cells. The gating of $\mathrm{CD}^{+} 8^{+}$,

Perforin $^{+}$, and the HLA-DR ${ }^{+}$population on antigen-specific $T$ cells is same as the gating on $\mathrm{CD}^{+}{ }^{+} \mathrm{T}$ cells. The percentage of tetramer ${ }^{+}$cells shown is within $\mathrm{CD}^{+}{ }^{+} \mathrm{T}$ cells. (B) Frequency of $\mathrm{HLA}-\mathrm{A}^{\star} 0201 \mathrm{M1}_{58-66}$ tetramer positive cells before and after each vaccine dose. (C) Expression of activation markers (CD38 and HLA-DR) and cytolytic marker (Perforin D48) on HLA-A*0201 M158-66 tetramer positive cells before and after each vaccine dose. Lines represent the percentage of tetramer positive cells with the noted markers. (D) Comparison of CD38 expression on CD8 ${ }^{+} \mathrm{T}$ cells before and after each vaccine dose in the vaccine virus-infected group (first vaccination: $n=13$; second vaccination: $n=11)$. $p$-Values were calculated using the Wilcoxon matched-pairs signed rank test. For the scatter dot plots, the line represents the median value. enhanced responses to seasonal influenza virus HAs, particularly $\mathrm{H} 1 \mathrm{HA}$, were higher than the responses to the H5 HA protein (Figure 4B), indicating that the H5N1 pLAIV preferentially boosted $\mathrm{T}$ cell responses to seasonal influenza HA proteins rather than $\mathrm{H} 5 \mathrm{~N} 1 \mathrm{HA}$ in some individuals.

As illustrated in Figure 5A, both study subjects ID23 and ID24 displayed responses to peptide HA1-56 from the H1 HA protein, and the responses were mainly elicited by $\mathrm{CD} 8^{+} \mathrm{T}$ cells. However, our ex vivo ELISPOT data showed that the T cells did not recognize the corresponding peptide from the H5 HA, known as HA559 (Figure 5B). Subsequently, we generated $\mathrm{CD} 8^{+} \mathrm{T}$ cell clones specific to the H1 HA1-56 peptide from study subject ID24 and tested their cross-reactivity to the H5 HA5-59 peptide. As shown in Figures 5C,D and Figure S1 in Supplementary Material, all three $\mathrm{T}$ cell clones were capable of degranulation and producing IFN- $\gamma$ and TNF- $\alpha$ when stimulated by peptide HA1-56. However, they did not show any responses to peptide HA5-59, even at a high peptide concentration. These data suggest that $\mathrm{T}$ cell responses to seasonal influenza HA proteins had low-level cross-reactivity to the $\mathrm{H} 5 \mathrm{HA}$, an example of original antigenic sin (OAS) for T cells.

\section{High Pre-Existing Cross-Reactive Responses to Internal Influenza Virus Proteins do not Restrict Infectivity of the Vaccine Virus}

On screening for $\mathrm{T}$ cell responses to internal influenza virus proteins, we observed strong cross-reactive responses to internal proteins of the $\mathrm{H} 5 \mathrm{~N} 1$ virus, especially $\mathrm{M}$ and NP, in some infected study subjects prior to immunization. For example, as illustrated in Figure 6A, study subjects ID27 and ID32 who were infected with the H5N1 pLAIV vaccine, showed strong T cell responses to the $\mathrm{M}$ protein before vaccination, with a level of IFN- $\gamma$ production $>600$ SFU $/ 10^{6}$ PBMCs. Among the study subjects infected with the pLAIV, pre-existing T cell responses targeting the NP protein were also detected in ID27, ID32, and ID34, with a magnitude $>250$ SFU $/ 10^{6}$ PBMCs. There was no significant difference in the pre-existing $\mathrm{T}$ cell responses targeting internal viral proteins $\mathrm{M}$ and NP between the pLAIV-infected and un-infected groups (Figures 6B,C, and data not shown). These data indicate that high pre-existing cross-reactive responses to internal influenza viral proteins are unlikely to have played a role in restricting the infectivity of the vaccine virus. 

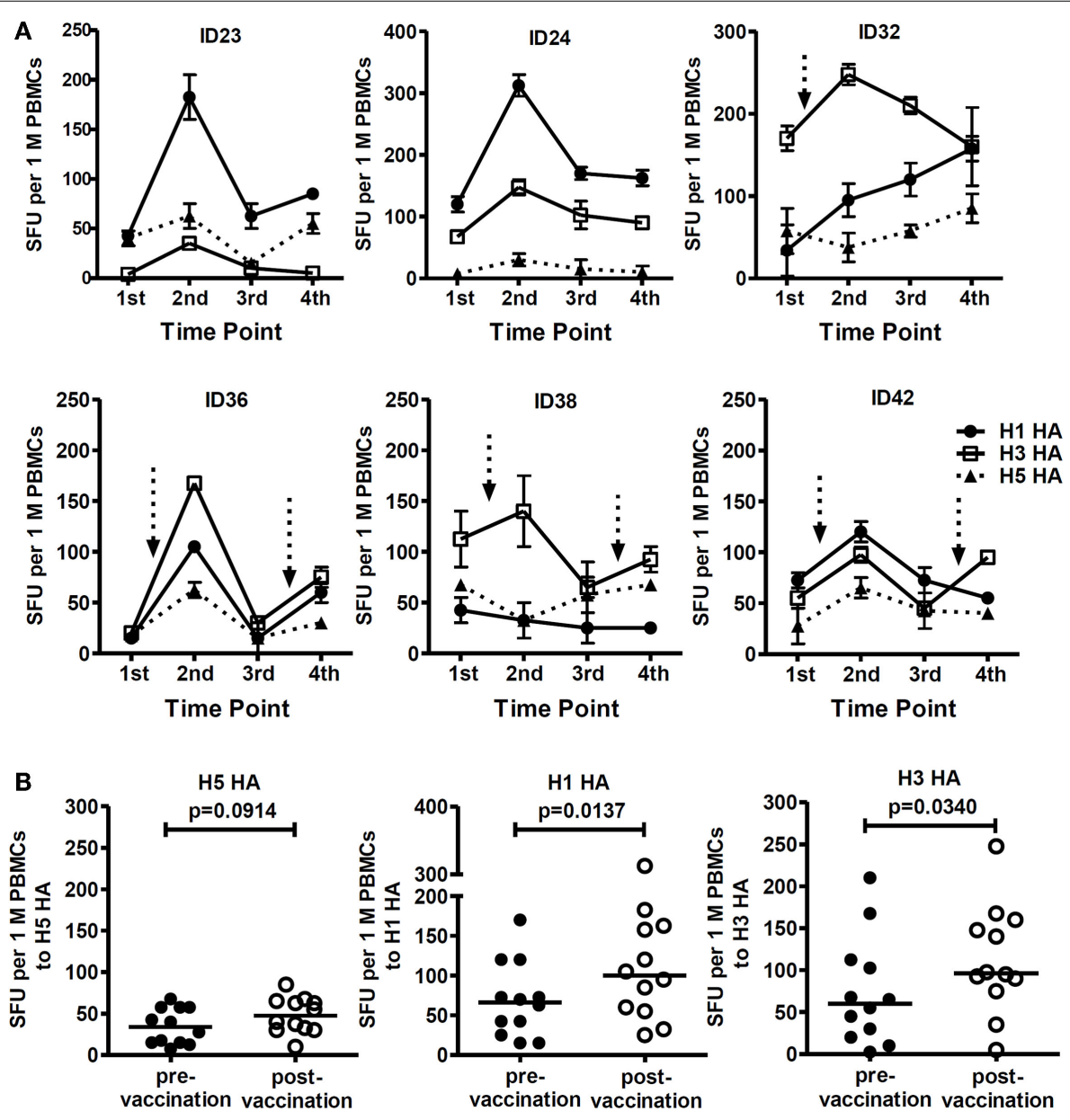

FIGURE 4 | T cell responses to seasonal influenza HA peptides were elevated after the first and second dose of the pLAIV. (A) T cell responses to $\mathrm{H} 1 \mathrm{HA}, \mathrm{H} 3 \mathrm{HA}$, and $\mathrm{H} 5 \mathrm{HA}$ peptides at all four time-points in six study subjects. $n=2$ replicates; Arrows represent documented vaccine virus infection.
(B) Comparison of $\mathrm{T}$ cell responses targeting $\mathrm{H} 5 \mathrm{HA}, \mathrm{H} 1 \mathrm{HA}$, and $\mathrm{H} 3 \mathrm{HA}$ preand post- first and second vaccination, $n=6$. $p$-Values were calculated using the Wilcoxon matched-pairs signed rank test. For the scatter dot plots, the line represents the median value.

\section{Discussion}

Vaccination with the H5N1 pLAIV stimulated modest influenzaspecific $\mathrm{T}$ cell responses in most vaccine recipients. The responses were in both $\mathrm{CD}^{+}$and $\mathrm{CD}^{+} \mathrm{T}$ cells and the $\mathrm{T}$ cells showed evidence of cytolytic function. There was no relationship between the $\mathrm{T}$ cell responses and other evidence that of pLAIV vaccine infection, either by PCR-detected shedding or a fourfold rise antibody titer. Although the H5N1 pLAIV was highly restricted in replication and was poorly immunogenic in the phase I clinical trial, we recently showed that the H5N1 pLAIV induced long-term immune memory (18). We detected a high titer, rapid antibody response in most of the study subjects following the administration of a single dose of an $\mathrm{H} 5 \mathrm{~N} 1$ inactivated subunit influenza vaccine (ISIV) almost 5 years after the initial H5N1 pLAIV (18). Interestingly, pLAIV priming of these antibody responses occurred even in the absence of significant vaccine virus shedding and immunogenicity measured by traditional end points in the initial phase I clinical trials of the H5N1 pLAIV (18). In the current study, indications of antigen exposure by significantly elevated $\mathrm{T}$ cell responses were observed after the first and/or second dose of pLAIV in most volunteers; these responses did not correlate either positively or negatively with the antibody responses following ISIV boost. In a separate study in Vietnam, we have detected $\mathrm{H} 5 \mathrm{~N} 1$-specific $\mathrm{T}$ cell responses in a village cohort with $\mathrm{H} 5 \mathrm{~N} 1$ virus exposure, regardless of the detection of antibodies (22). Thus, it is likely that exposure to infectious influenza virus can sometimes stimulate $\mathrm{CD}^{+} \mathrm{T}$ cell responses without inducing antibody responses or infecting sufficient cells in the respiratory tract to be detectable by PCR or virus culture. Detection of influenza virus-specific $\mathrm{T}$ cell responses may serve as an additional marker for subclinical H5N1 virus infection in humans.

$\mathrm{T}$ cell immune responses were detected targeting internal viral proteins, which are highly conserved between different influenza virus strains. These highly cross-reactive $\mathrm{T}$ cells are likely to confer broader or potentially "universal" protection against a wide range of influenza viruses (19). T cell responses, especially cross-reactive $\mathrm{T}$ cell responses, correlate with protection in several studies, including our own $(14,15)$. Although very low antibody 

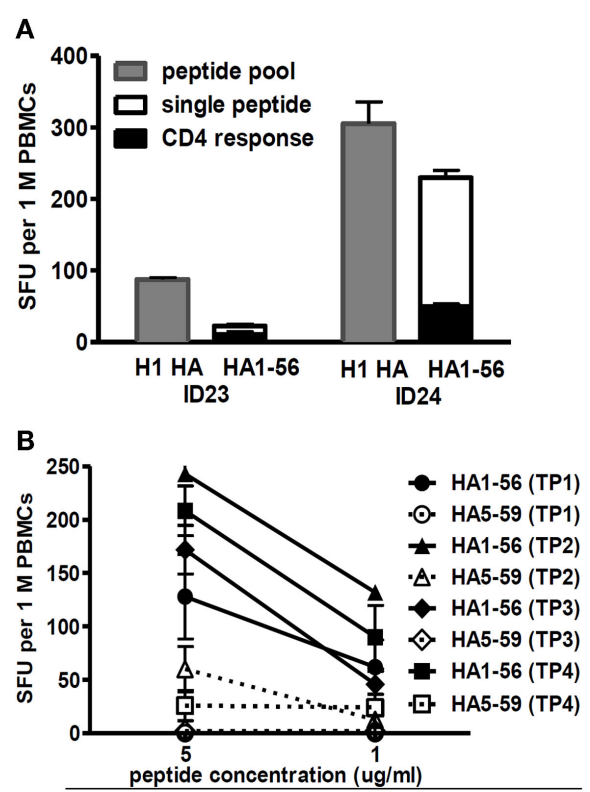
Peptide Strain Peptide sequence

HA1-56 H1N1 NKLERR/MENLNKKVDDGF HA5-59 H5N1 N/LERR/ENLNKKMEDGF

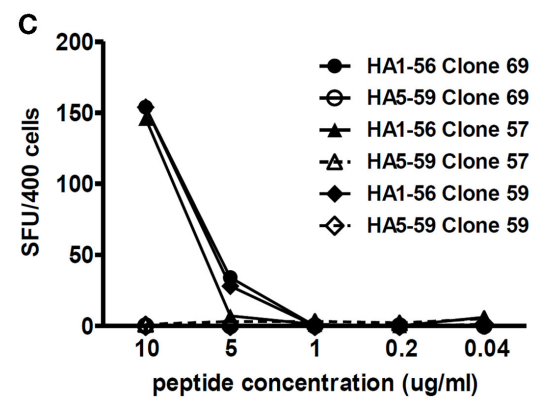

FIGURE 5 | T cell responses to seasonal influenza HA proteins showed a low level of cross-reactivity to H5 HA. (A) T cell responses to peptide pools, single peptide, and responses to single peptide elicited by $\mathrm{CD}^{+}{ }^{+} \mathrm{T}$ cells from study subjects ID23 at time point 2 and ID24 at time point 4. $n=3$ replicates. (B) Cross-recognition of peptides HA1-56 and HA5-59 by T cells from study subject ID24 at all four time points. $n=3$
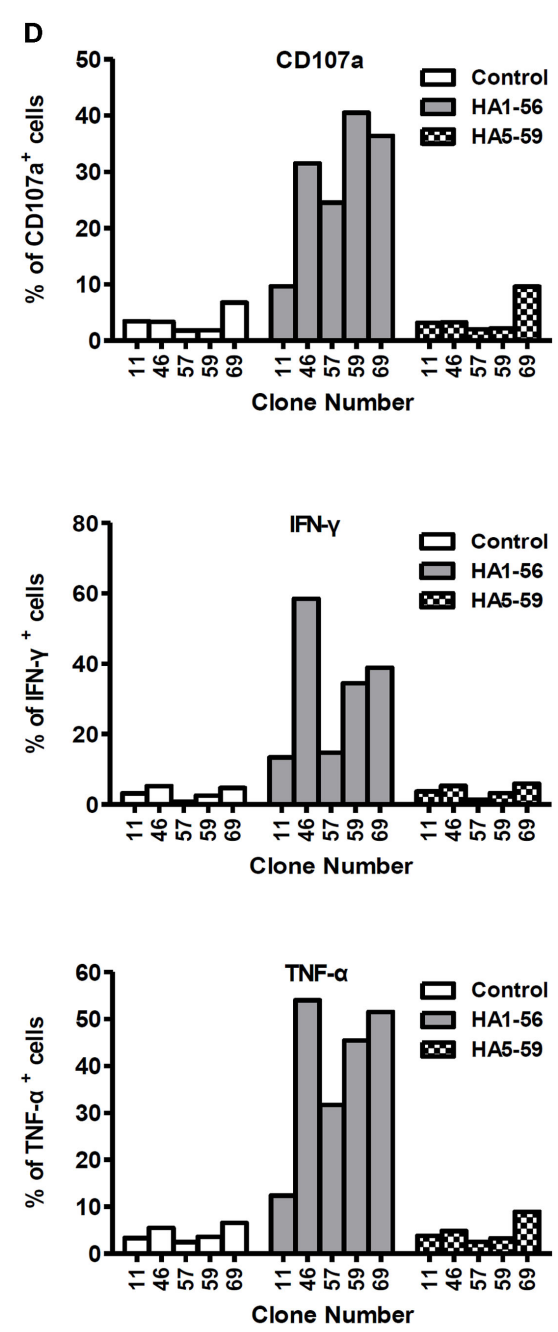

replicates. Amino acids differing between HA1-56 and HA5-59 are shown in gray italics. (C,D) Cross-recognition of peptides HA1-56 and HA5-59 by $T$ cell clones generated from study subject ID24. The cross-reactivity of $T$ cell clones was assessed by IFN- $\gamma$ ELISPOT using titrated peptides

(C), degranulation (CD107a expression), and intracellular TNF $\alpha$ and IFN- $\gamma$ production (D).

phenomenon. Original antigenic sin in T cells in humans was first described for dengue viruses by Mongkolsapaya et al. (23) and implies that the response to a secondary infection by a dengue virus is dominated by the proliferation of cross-reacting memory $T$ cells induced by primary infection with a different viral strain, which is of lower affinity for the secondary viral antigen. However, whether this will be to the benefit or the detriment of the host remains unanswered.

Finally, the presence of high level pre-immunization $\mathrm{T}$ cell responses in three volunteers did not prevent boosting of $\mathrm{T}$ cell responses. Therefore, this does not appear to be the reason why the pLAIV did not infect all the study subjects. However, as discussed above, the vaccine boosted $\mathrm{T}$ cell responses in the absence of detectable virus shedding or a rise in antibody titer. It is likely therefore that low-level infection by the attenuated pLAIV rather variably stimulates both $\mathrm{T}$ and $\mathrm{B}$ cell responses. 

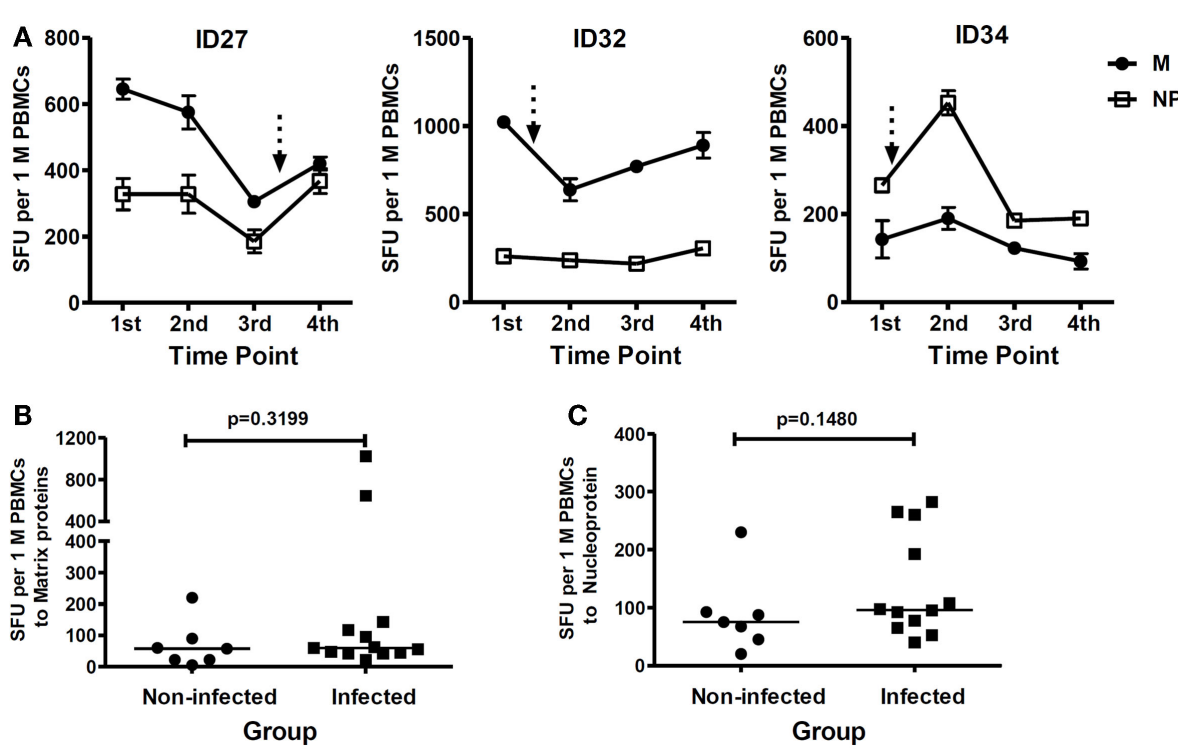

FIGURE 6 | T cell responses targeting H5N1 internal viral proteins (A) Examples of the study subjects from the vaccine virus-infected group (ID27, ID32, and ID34) who showed high pre-existing cross-reactive T cell responses. $n=2$ replicates. Arrows represent documented vaccine virus infection. (B) Comparison of pre-existing cross-reactive $T$ cell responses targeting the viral M proteins between the vaccine virus-infected $(n=13)$ and un-infected ( $n=7$ ) study subjects. (C) Comparison of pre-existing cross-reactive T cell responses targeting NP protein between the vaccine virus-infected $(n=12)$ and un-infected $(n=7)$ study subjects. Study subject ID29 was excluded because of limited cell numbers. $p$-values were calculated using the Mann-Whitney test. For the scatter dot plots $\mathbf{( B , C )}$, the line represents the median value.

\section{Acknowledgments}

This research was supported in part by the Medical Research Council, UK and the Division of Intramural Research, NIAID, NIH.

\section{References}

1. Webster RG, Govorkova EA. Continuing challenges in influenza. Ann N Y Acad Sci (2014) 1323:115-39. doi:10.1111/nyas.12462

2. Epstein SL, Lo CY, Misplon JA, Lawson CM, Hendrickson BA, Max EE, et al. Mechanisms of heterosubtypic immunity to lethal influenza A virus infection in fully immunocompetent, T cell-depleted, beta2-microglobulin-deficient, and J chain-deficient mice. J Immunol (1997) 158:1222-30.

3. Gao HN, Lu HZ, Cao B, Du B, Shang H, Gan JH, et al. Clinical findings in 111 cases of influenza A (H7N9) virus infection. N Engl J Med (2013) 368:2277-85. doi:10.1056/NEJMoa1305584

4. Gao R, Cao B, Hu Y, Feng Z, Wang D, Hu W, et al. Human infection with a novel avian-origin influenza A (H7N9) virus. N Engl J Med (2013) 368:1888-97. doi:10.1056/NEJMoa1304459

5. Coelingh KL, Luke CJ, Jin H, Talaat KR. Development of live attenuated influenza vaccines against pandemic influenza strains. Expert Rev Vaccines (2014) 13:855-71. doi:10.1586/14760584.2014.922417

6. Ashkenazi S, Vertruyen A, Aristegui J, Esposito S, McKeith DD, Klemola T, et al. Superior relative efficacy of live attenuated influenza vaccine compared with inactivated influenza vaccine in young children with recurrent respiratory tract infections. Pediatr Infect Dis J (2006) 25:870-9. doi:10.1097/01.inf.0000237829. 66310.85

7. Belshe RB, Edwards KM, Vesikari T, Black SV, Walker RE, Hultquist M, et al. Live attenuated versus inactivated influenza vaccine in infants and young children. N Engl J Med (2007) 356:685-96. doi:10.1056/NEJMoa065368

8. Fleming DM, Crovari P, Wahn U, Klemola T, Schlesinger Y, Langussis A, et al. Comparison of the efficacy and safety of live attenuated cold-adapted influenza vaccine, trivalent, with trivalent inactivated influenza virus vaccine

\section{Supplementary Material}

The Supplementary Material for this article can be found online at http://journal.frontiersin.org/article/10.3389/fimmu.2015. 00287/abstract

in children and adolescents with asthma. Pediatr Infect Dis J (2006) 25:860-9. doi:10.1097/01.inf.0000237797.14283.cf

9. Karron RA, Talaat K, Luke C, Callahan K, Thumar B, Dilorenzo S, et al. Evaluation of two live attenuated cold-adapted $\mathrm{H} 5 \mathrm{~N} 1$ influenza virus vaccines in healthy adults. Vaccine (2009) 27:4953-60. doi:10.1016/j.vaccine.2009.05.099

10. Black S, Nicolay U, Vesikari T, Knuf M, Del Giudice G, Della Cioppa G, et al. Hemagglutination inhibition antibody titers as a correlate of protection for inactivated influenza vaccines in children. Pediatr Infect Dis J (2011) 30:1081-5. doi:10.1097/INF.0b013e3182367662

11. Gravenstein S, Drinka P, Duthie EH, Miller BA, Brown CS, Hensley M, et al. Efficacy of an influenza hemagglutinin-diphtheria toxoid conjugate vaccine in elderly nursing home subjects during an influenza outbreak. J Am Geriatr Soc (1994) 42:245-51. doi:10.1111/j.1532-5415.1994.tb01746.x

12. Ohmit SE, Petrie JG, Cross RT, Johnson E, Monto AS. Influenza hemagglutination-inhibition antibody titer as a correlate of vaccine-induced protection. J Infect Dis (2011) 204:1879-85. doi:10.1093/infdis/jir661

13. Bandell A, Woo J, Coelingh K. Protective efficacy of live-attenuated influenza vaccine (multivalent, Ann Arbor strain): a literature review addressing interference. Expert Rev Vaccines (2011) 10:1131-41. doi:10.1586/erv.11.73

14. McMichael AJ, Gotch FM, Noble GR, Beare PA. Cytotoxic T-cell immunity to influenza. N Engl J Med (1983) 309:13-7. doi:10.1056/NEJM198307073090103

15. Wilkinson TM, Li CK, Chui CS, Huang AK, Perkins M, Liebner JC, et al. Preexisting influenza-specific CD4+ T cells correlate with disease protection against influenza challenge in humans. Nat Med (2012) 18:274-80. doi:10.1038/ nm.2612

16. Epstein SL. Prior H1N1 influenza infection and susceptibility of Cleveland family study participants during the H2N2 pandemic of 1957: an experiment of nature. J Infect Dis (2006) 193:49-53. doi:10.1086/498980 
17. Schotsaert M, Saelens X, Leroux-Roels G. Influenza vaccines: T-cell responses deserve more attention. Expert Rev Vaccines (2012) 11:949-62. doi:10.1586/erv. 12.71

18. Talaat KR, Luke CJ, Khurana S, Manischewitz J, King LR, McMahon BA, et al. A live attenuated influenza $\mathrm{A}(\mathrm{H} 5 \mathrm{~N} 1)$ vaccine induces long-term immunity in the absence of a primary antibody response. J Infect Dis (2014) 209:1860-9. doi:10.1093/infdis/jiu123

19. Lee LY, Ha do LA, Simmons C, de Jong MD, Chau NV, Schumacher R, et al. Memory $\mathrm{T}$ cells established by seasonal human influenza A infection crossreact with avian influenza A (H5N1) in healthy individuals. J Clin Invest (2008) 118:3478-90. doi:10.1172/JCI32460

20. Dong T, Moran E, Vinh Chau N, Simmons C, Luhn K, Peng Y, et al. High pro-inflammatory cytokine secretion and loss of high avidity cross-reactive cytotoxic T-cells during the course of secondary dengue virus infection. PLoS One (2007) 2:e1192. doi:10.1371/journal.pone. 0001192

21. Dong T, Stewart-Jones G, Chen N, Easterbrook P, Xu X, Papagno L, et al. HIV-specific cytotoxic $\mathrm{T}$ cells from long-term survivors select a unique $\mathrm{T}$ cell receptor. J Exp Med (2004) 200:1547-57. doi:10.1084/ jem.20032044
22. Powell TJ, Fox A, Peng Y, Quynh Mai le T, Lien VT, Hang NL, et al. Identification of H5N1-specific T-cell responses in a high-risk cohort in Vietnam indicates the existence of potential asymptomatic infections. J Infect Dis (2012) 205:20-7. doi:10.1093/infdis/jir689

23. Mongkolsapaya J, Dejnirattisai W, Xu XN, Vasanawathana S, Tangthawornchaikul N, Chairunsri A, et al. Original antigenic sin and apoptosis in the pathogenesis of dengue hemorrhagic fever. Nat Med (2003) 9:921-7. doi:10. $1038 / \mathrm{nm} 887$

Conflict of Interest Statement: The authors declare that the research was conducted in the absence of any commercial or financial relationships that could be construed as a potential conflict of interest.

Copyright $\odot 2015$ Peng, Wang, Talaat, Karron, Powell, Zeng, Dong, Luke, McMichael, Subbarao and Dong. This is an open-access article distributed under the terms of the Creative Commons Attribution License (CC BY). The use, distribution or reproduction in other forums is permitted, provided the original author(s) or licensor are credited and that the original publication in this journal is cited, in accordance with accepted academic practice. No use, distribution or reproduction is permitted which does not comply with these terms. 